\title{
Truthfulness and Gricean Cooperation ${ }^{*}$
}

\author{
Andreas Stokke \\ Forthcoming in Grazer Philosophische Studien
}

\begin{abstract}
This paper examines the Gricean view that quality maxims take priority over other conversational maxims. It is shown that Gricean conversational implicatures are routinely inferred from utterances that are recognized to be untruthful. It is argued that this observation falsifies Grice's original claim that hearers assume that speakers are obeying other maxims only if the speaker is assumed to be obeying quality maxims, and furthermore the related claim that hearers assume that speakers are being cooperative only to the extent that they assume they are being truthful.
\end{abstract}

\section{Introduction}

It is a platitude that conversation involves cooperation. Slightly more specifically, philosophers and linguists typically take for granted that the ways we communicate with each other in conversation rely on speakers and hearers cooperating on efficiently getting information across, or something to the same effect. By far, the most influential account of communicative cooperation is also the one that can be said to be responsible for establishing the paradigm of understanding conversations as cooperative enterprises in the first place, namely the account given by Paul Grice (1989).

Grice set out an understanding of conversation as guided by his Cooperative Principle and conversational maxims, the latter being principles the observation of

\footnotetext{
*I am grateful to Matt Benton, Chris Gauker, Torfinn Huvenes, Eliot Michaelson, Anders Schoubye, and Jonas Åkerman for valuable comments and suggestions.
} 
which ensure, or at least tend to ensure, cooperation in conversation. Grice also held that cooperation in conversation is closely tied to truthfulness. In particular, Grice thought that, among the maxims of conversation, certain maxims of quality - admonishing speakers to be truthful - have a special status. Briefly put, Grice claimed that speakers are assumed to be observing other maxims only if they are assumed to be obeying quality maxims.

I want to argue here that this view of cooperation does not square with the facts about conversational practices. In particular, I want to target the claim that, when hearers make the kind of inferences from what speakers say that Grice was interested in, they assume that speakers are being cooperative only to the extent that they assume they are being truthful. My main motivation for rejecting this idea is the observation that inferences that have the marks of inferences of Gricean conversational implicatures are often made by hearers, even when they recognize that the speaker is violating quality maxims, and as such is being untruthful. Here is an example where this happens:

Louise knows that Thelma has been drinking, but Thelma doesn't realize that Louise knows this.

(1) Louise. Are you OK to drive?

Thelma. I haven't been drinking.

As I will argue, even though Louise knows that Thelma is being untruthful, she nevertheless infers that Thelma meant to convey that she is OK to drive.

My focus is chiefly on the kind of inferences hearers draw based on observation of what speakers say, and less on what speakers intend, or can reasonably intend, to be conveyed by their utterances. It has been pointed out - e.g., by Jennifer Saul (2002) - that these two may come apart. A speaker might want to convey a particular implicature, even if the hearer fails to infer it, and a hearer might infer unintended implicatures from what a speaker says. I confine myself to cases in which what the speaker intends to convey coincides with what the hearer infers from what she says. My argument will be that hearers often make inferences intended by speakers, based on assumptions of cooperation along Gricean lines, but which do not involve assumptions of truthfulness.

Section 2 reviews Grice's view concerning the priority of quality maxims and the kind of example I take to be evidence against it. In section 3 I consider a number of ways the Gricean might respond to this evidence. I argue that there are inferences hearers make that are best explained as proceeding via the assumption that the speaker is cooperating, but which do not involve assumptions about 
the speaker's truthfulness. Section 4 argues that the relevant inferences have the features of inferences of Gricean conversational implicatures and briefly discusses some consequences for how to understand the kind of cooperation involved in conversation.

\section{Grice on the Priority of Quality}

\subsection{The Gricean Category of Quality}

Grice's Cooperative Principle was stated as follows (Grice, 1989, 26):

\section{Cooperative Principle}

Make your contribution such as is required, at the stage at which it occurs, by the accepted purpose or direction of the talk exchange in which you are engaged.

In turn, the maxims were divided into four categories, Quantity, Quality, Relation, and Manner. Among these the category of Quality included a supermaxim and two specific maxims (Grice, 1989, 27):

Supermaxim of Quality: Try to make your contribution one that is true.

First Maxim of Quality: Do not say what you believe to be false.

Second Maxim of Quality: Do not say that for which you lack adequate evidence.

Here we will only be concerned with the Supermaxim of Quality and the First Maxim of Quality.

Grice held that the First Maxim of Quality and the Supermaxim of Quality enjoy a special status in relation to the other maxims and the Cooperative Principle. In "Logic and Conversation," immediately after presenting the maxims, Grice comments,

[I]t might be felt that the importance of at least the first maxim of Quality is such that it should not be included in a scheme of the kind I am constructing; other maxims come into operation only on the assumption that this maxim of Quality is satisfied. While this may be correct, so far as the generation of implicatures is concerned it seems to play a role not totally different from the 
other maxims, and it will be convenient, for the present at least, to treat it as a member of the list of maxims. (Grice, 1989, 27)

A major task for this paper will be to examine how to understand the central claim encapsulated in this passage, that is, the suggestion that "other maxims come into operation only on the assumption that [the First Maxim of Quality] is satisfied." But it appears at first sight that Grice thinks that the kind of communication that is to be seen as guided by the maxims, in some sense, relies on the assumption that the speaker is not saying something she believes to be false.

This idea is reinforced in the "Retrospective Epilogue," where Grice wrote,

The maxim of Quality, enjoining the provision of contributions which are genuine rather than spurious (truthful rather than mendacious), does not seem to be just one among a number of recipes for producing contributions; it seems rather to spell out the difference between something's being and (strictly speaking) failing to be, any kind of contribution at all. (Grice, 1989, 371)

By "The maxim of Quality," in this passage, Grice presumably has in mind the Supermaxim of Quality. This is suggested by his characterizaton of it as pertaining to "contributions," rather than to what is said more specifically. Similarly, the Cooperative Principle is explicitly a principle about contributions. For Grice, contributions comprised both things that are said, or asserted, and things that are conversationally implied. One way of understanding this passage from the "Retrospective Epilogue," therefore, is to see it as suggesting that unless one is aiming to make a truthful contribution, one cannot be seen to be cooperating in the sense intended by the Cooperative Principle. I will return to this idea concerning cooperation later (see section 3.2). First, I want to look at the former passage, concerning the relation between the First Maxim of Quality and the other maxims.

\subsection{Violating and Flouting Quality Maxims}

A first stab at how to understand Grice's suggestion in the passage from "Logic and Conversation" quoted above might be as follows (where $H$ is the hearer and $S$ is the speaker):

(I) $H$ assumes that $S$ is trying to satisfy other maxims in producing an utterance $u$ only if $H$ assumes that $S$ satisfies the First Maxim of Quality in producing $u$. 
This is one way of reading Grice's suggestion that "other maxims come into operation only on the assumption that [the First Maxim of Quality] is satisfied." (1989, 27)

The immediate problem with (I) is that it is arguably in conflict with the Gricean understanding of a range of cases in which the First Maxim of Quality is exploited in order to generate conversational implicatures. These include tropes like irony, metaphor, meiosis, and hyperbole (see Grice, 1989, 34-35). Take Grice's well-known example of the first of these:

X, with whom A has been on close terms until now, has betrayed a secret of A's to a business rival. A and his audience both know this. A says $X$ is a fine friend. (Grice, 1989, 34)

In this case the hearer sees that the speaker is not satisfying the First Maxim of Quality. So according to (I), she should not assume that the speaker is trying to satisfy any other maxims in making the utterance. But if so, on the Gricean picture, the hearer should not infer that the speaker wants to convey something different from what she said. ${ }^{1}$ In particular, the Gricean treatment of these cases assumes that the hearer takes the speaker as trying to satisfy the Supermaxim of Quality. When A says that $X$ is a fine friend, the hearer should think that the speaker wants to satisfy the Supermaxim of Quality, and in this way infer that she wants to implicate that $\mathrm{A}$ is not a fine friend.

The obvious response to this is that, according to Grice's conception of irony, metaphor, meiosis, and hyperbole, these are all cases in which the First Maxim of Quality is flouted. For Grice, cases that give rise to inferences of implicatures are cases in which the speaker violates maxims in a way that is intended to be noticed by the speaker and thereby to trigger the kind of reasoning that is expected to terminate in the inference of an implicature.

More generally, since irony and the other tropes involve flagrantly saying something one believes to be false, this is presumably not the kind of untruthfulness that a Gricean would take to be a hindrance to cooperative communication. And in particular, if the Gricean is right that hearers' inferences of implicatures turn on assumptions of truthfulness, it is reasonable to think that such assumptions are

\footnotetext{
${ }^{1}$ Grice held that, in cases like irony, the speaker has not said, but "has made as if to say," (Grice, $1989,34)$ the literal content of her utterance. The reason for this is that Grice thought of what is said as akin to how some think of assertion. In this paper I use the notion of saying in a loose sense, since nothing will hang on this. So, for instance, I allow myself to assume that ironic speakers say the literal contents of their utterance, even if they do not assert it. For discussion of this, see, e.g., Neale (1992), Stokke (2013).
} 
not defeated by a speaker's use of tropes such as irony, metaphor, meiosis, and hyperbole.

So, since in these kinds of cases the violation of the First Maxim of Quality is done in such a way as to make the hearer notice the violation, the claim that the First Maxim of Quality is a prerequisite for the operation of the other maxims is better understood as not pertaining to cases in which it is flouted for the purpose of generating implicatures.

Let us stipulate that by disregarding a maxim, we mean violating it but not by flouting it. To disregard a maxim is to disobey it, but not in the way that is intended to call attention to itself, which Grice identified as exploiting maxims in order to generate implicatures. Given this, one proposal for understanding the Gricean claim concerning the priority of quality maxims is as in (II). ${ }^{2}$

(II) $H$ assumes that $S$ is trying to satisfy other maxims in producing an utterance $u$ only if $H$ assumes that $S$ is not disregarding the First Maxim of Quality in producing $u$.

According to (II), assuming that someone is trying to satisfy maxims requires assuming that they are speaking truthfully, while allowing that someone may blatantly and openly speak untruthfully in order to generate implicatures by exploiting quality maxims.

\subsection{Implicatures Inferred from Detected Quality Violations}

A situation in which a hearer can see that a speaker is flouting a maxim is not the only kind of situation in which a hearer can see that a speaker is violating a maxim. The hearer might be able to see that the speaker is violating a maxim but is not doing so in the kind of blatant way that is intended to trigger inferences of implicatures. If a hearer can see that a speaker is violating a maxim and that the speaker thinks that the hearer will not notice, the speaker is not flouting the maxim.

Consequently, (II) implies that if the hearer can see that the speaker thinks that her violation of the First Maxim of Quality will go unnoticed, the hearer will not try to reconcile that she said what she did with an assumption that she is observing maxims other than the First Maxim of Quality.

However, at least at first sight, this does not square with the facts about how utterances are interpreted in this kind of situation. Even if the hearer can see that

\footnotetext{
${ }^{2}$ See Benton (in press) for a suggestion of this kind.
} 
the speaker is being covertly untruthful, she may still take the speaker as having implicated something other than what she said. Consider our example from above:

Louise knows that Thelma has been drinking, but Thelma doesn't realize that Louise knows this.

(1) Louise. Are you OK to drive?

Thelma. I haven't been drinking.

In this case Louise will take Thelma as having implicated that she is OK to drive. Yet Louise knows that Thelma is violating the First Maxim of Quality, even though she is not doing so by flouting the maxim. ${ }^{3}$ So, since the implicature is still inferred, this is evidence against (II).

In support of this conclusion, we can note that the Gricean will agree with this description of the analogous, truthful cases, as in (2).

Thelma hasn't been drinking.

(2) Louise. Are you OK to drive?

Thelma. I haven't been drinking.

The Gricean will explain (2) as a case of conversational implicature, more precisely a case of implicature inferred via the assumption that Thelma is trying to satisfy the Maxim of Relation (Grice, 1989, 27).

\section{Maxim of Relation}

Be relevant.

Note that, in both (1) and (2), the inference the hearer makes is also intended by the speaker. In the terminology of Saul (2002), both are case in which an "uttererimplicature" coincides with an "audience-implicature." By the same token, even if writers like Stephen Neale (1992) are right that being intended by the speaker is a necessary condition on conversational implicature, both cases qualify. (I return to this in section 4.1).

\footnotetext{
${ }^{3}$ If one prefers, one may reconstruct the case so as to specify that Louise does not know prior to Thelma's utterance that she has been drinking and hence already knows the answer to the question she is asking. For example, one can think of cases in which Louise recognizes from Thelma's utterance itself that she has been drinking, e.g., she is slurring her words, or the like. Thanks to Eliot Michaelson for this suggestion.
} 
Given that the Gricean will count (2) as a case of conversational implicature, to vindicate the claim in (II), the Gricean needs to motivate that there is a relevant difference between (1) and (2). In particular, the Gricean needs to argue that, despite the apparent similarities mentioned above, (1) should not be classified as a case of conversational implicature, or more generally as the kind of inference that Grice was interested in accounting for. In the next section, I will argue that there is no convincing way of making this kind of argument.

\section{Inference, Cooperation, and Truthfulness}

\subsection{Repairing Maxim Violations}

One potential way of arguing for a difference between (1) and (2) starts from the observation that the hallmark of a Gricean inference is that it aims at establishing that maxims that are violated at the level of what is said are satisfied at the level of what is meant or implied. As we might say, when maxims are violated at the level of what is said, a Gricean inference should repair such violations at the level of what is implied.

In (1) Louise recognizes that Thelma is violating the First Maxim of Quality at the level of what is said. Hence, it might be objected that Louise's inference should aim at repairing this violation at the level of what is implied. In particular, Louise's inference should establish that Thelma is satisfying the Supermaxim of Quality. ${ }^{4}$ However, in (1), Louise's inference does not establish that Thelma is satisfying the Supermaxim of Quality, since she can see that what is implied is something Thelma believes to be false (that she is OK to drive). So the violation of the First Maxim of Quality is not repaired. Hence, so the objection goes, the inference involved in (1) is not of the kind the Gricean wants to associate with conversational implicatures.

In reply to this objection we should note that, while inferring implicatures is indeed a process that centrally aims at repairing maxim violations, this kind of repair strategy is directed at floutings of maxims. An implicature is inferred, according to the Gricean scheme, when the hearer can see that the speaker is blatantly and

\footnotetext{
${ }^{4}$ The quality maxims have the feature that while the First Maxim of Quality and the Second Maxim of Quality pertain to what is said, the Supermaxim of Quality is explicitly a principle concerning contributions. Since Grice took contributions to include both what is said and what is implied, the Supermaxim of Quality plays the role of the maxim that is seen to be satisfied at the level of what is implied by implicatures such as those involved in irony, metaphor, etc. For other maxims, e.g., the Maxim of Relation, the repair will target the maxim itself.
} 
noticeably failing to comply with one or more maxims, and hence that she is doing so precisely with the intention of triggering the inference of the implicature. Yet, in (1), the First Maxim of Quality is not flouted but is violated in a covert way, albeit the deceit is unsuccessful. In the terminology introduced above, Thelma's utterance in (1) disregards the First Maxim of Quality. So, since the First Maxim of Quality is not flouted, in this case, why should the hearer try to repair the violation at the level of what is implied, that is, why should she assume that the speaker is trying to satisfy the Supermaxim of Quality?

Moreover, Thelma does flout a maxim at the level of what is said, namely Relation, and this violation is repaired by the inference of the implicature that Thelma is OK to drive. Inferring the implicature that Thelma is OK to drive is a way of squaring what she said, i.e., that she has not been drinking, with the presumption that she is trying to obey Relation. In this case, the measure of what is relevant is naturally taken to be given by what constitutes an answer to the question that was explicitly asked, i.e., "Are you OK to drive?" Since there are only two answers to this question - yes or no - inferring the implicature is a way of establishing that while what she said is not strictly speaking relevant, Relation is nevertheless satisfied at the level of what is implied.

\subsection{Obeying Maxims and Being Cooperative}

A more promising response to our claim that the inference involved in (1) is relevantly parallel to the inference involved in (2) is to object that the former inference cannot be seen as proceeding via an appeal to the Cooperative Principle. Grice took inferences of implicatures to centrally rely on the assumption that the speaker is cooperating. For example, towards the end of "Logic and Conversation," Grice says,

[T]o calculate a conversational implicature is to calculate what has to be supposed in order to preserve the supposition that the Cooperative Principle is being observed [...]. (Grice, 1989, 39-40)

Similarly, in providing his "general pattern for the working out of a conversational implicature," Grice explicitly includes an appeal to the Cooperative Principle. ${ }^{5}$ The general pattern is described as follows:

\footnotetext{
${ }^{5}$ Grice makes essentially the same remark in “Utterer's Meaning and Intentions" (see Grice, 1989, 86).
} 
He has said that $p$; there is no reason to suppose that he is not observing the maxims, or at least the Cooperative Principle; he could not be doing this unless he thought that $q$; he knows (and knows that I know that he knows) that I can see that the supposition that he thinks that $q$ is required; he has done nothing to stop me thinking that $q$; he intends me to think, or is at least willing to allow me to think, that $q$; and so he has implicated that $q$. (Grice, 1989, 31)

The same choice of words is used immediately above, when Grice states that someone implicates something only if "he is to be presumed to be observing the conversational maxims, or at least the Cooperative Principle [...]." (Grice, 1989, 30)

So perhaps the suggestion that Gricean inferences involve assumptions of truthfulness should be understood as not pertaining to reasoning about whether the speaker is obeying maxims, rather than to reasoning about whether the speaker is being cooperative at all. We might try to restate the Gricean claim as in (III).

(III) $H$ assumes that $S$ is trying to satisfy the Cooperative Principle, in producing an utterance $u$ only if $H$ assumes that $S$ is not disregarding the First Maxim of Quality in producing $u$.

If the Gricean claim about truthfulness and cooperation is to be understood in this way, one might suggest trying to distinguish between (1) and (2) by agreeing that both are inferred via an assumption that the speaker is obeying Relation, while insisting that only in the latter case does the hearer also assume that the speaker is being cooperative.

In support of this line of argument, one might point to the fact that, even though Grice thought of the maxims as norms that implement cooperation in conversation, he is careful to qualify his statement of this idea. Grice says that the maxims are principles "the following of which will, in general, yield results in accordance with the Cooperative Principle." (1989, 26, emphasis added) Perhaps we should think of (1) as a case where following the maxims does not yield compliance with the Cooperative Principle.

There are two main problems with this strategy for differentiating between (1) and (2). First, if it is agreed that the inference in (1) proceeds via the assumption that the speaker is trying to satisfy Relation, the Gricean has arguably given up the original view concerning the centrality of quality maxims. Conceding that the inference in (1) proceeds by assuming the speaker is obeying Relation is in conflict with Grice's suggestion that "other maxims come into operation only on the assumption that [the First Maxim of Quality] is satisfied." (Grice, 1989, 27) 
Second, it is hard to see how to understand the suggestion that, in (1), Louise assumes that Thelma is trying to satisfy Relation but does not assume that she is trying to comply with the Cooperative Principle. This would amount to the claim that while Louise assumes that Thelma is trying to be relevant, she is not assuming that Thelma is trying to make her contribution such as is required, at the stage at which it occurs, by the accepted purpose or direction of the talk exchange in which she is engaged. It is at best unclear how to make sense of this idea.

Hence, despite the fact that, in (1), Thelma is being untruthful, it is not easy to see this as a case in which compliance with Relation does not yield compliance with the Cooperative Principle. Instead, it might be proposed that the reason Thelma cannot be seen as being cooperative is that, since she is being untruthful, she is not speaking in a way that counts as what Grice thinks of as making a contribution at all. We have already seen evidence for this way of thinking in Grice's statement, from the "Retrospective Epilogue," that the Supermaxim of Quality marks the difference between something being a (genuine) contribution or not (see Grice, 1989, 371).

However, it is question-begging to appeal to this idea at this point in the dialectics. We have pointed to evidence against the claim that the relevant inferences are made only under the assumption that the speaker is being truthful. The potential response under consideration is that, while Louise assumes that Thelma is obeying Relation, she does not assume that Thelma is obeying the Cooperative Principle, and hence the inference is sufficiently different from those involved in truthful cases. But to motivate this proposal by the claim that making a contribution at all requires being truthful - and hence that assuming that someone is making a contribution requires assuming they are being truthful - is to beg the question. It is no good to simply insist that making cooperative contributions requires being truthful.

As a final option at this point, one might suggest distinguishing between different senses of cooperation. One might think that Grice's original notion of cooperation should be understood as applying to discourse that is ultimately aimed at exchanging truths. ${ }^{6}$ On the other hand, since inferences that appear to have all the trademarks of Gricean inferences are routinely drawn in spite of known untruthfulness, this might suggest looking for a way of understanding cooperativeness such that being cooperative, in the relevant sense, does not require obeying quality maxims.

A view of this kind is suggested by Richmond Thomason (1990). Agreeing

\footnotetext{
${ }^{6}$ See Grice $(1989,371)$ for some support for this interpretation.
} 
that "implicatures are possible in situations that can only be described as hostile or uncooperative" $(1990,355)$, Thomason suggests that we should react by understanding the kind of cooperation involved in conversations as "a shared sense of where the conversation has been and of where it is headed: the common plan of the conversation." (1990, 356)

One can see the kind of cooperation that, according to the Gricean program, is necessary for generating implicatures - and for communicating more generally - as cooperation toward the goal of sharing truths. If so, then one cannot regard someone who violates quality maxims as being cooperative. Yet one can also understand cooperation in a conversation as cooperation toward efficient information-sharing, broadly understood. ${ }^{7}$

Given this kind of distinction, contributions might be seen as "genuine," in the Gricean sense, only if the comply with the truth-oriented sense of cooperation. Hence, Thelma's utterance will be seen as not genuine, in this sense. But on the other hand, the implicature that is inferred from it might be explained in terms of cooperation in the broader, Thomasonian sense.

This line of thought, however, is not a threat to the argument I am pursuing. It still amounts to accepting that implicatures may be inferred by way of a presumption that the speaker is being cooperative (in one sense), even when the hearer can see that the speaker is not being truthful in the sense of obeying quality maxims. To be sure, the Gricean might reserve a narrow sense of cooperation and declare that untruthful contributions are not cooperative, in this sense, and hence should be seen as "spurious." But this does not explain away implicatures that are inferred from untruthful contributions. (I return later, in 4.1, to the issue of implicaturegeneration without presumptions of cooperation.)

The Gricean is in need of a convincing way of motivating that, while the inference in (2) involves an assumption of cooperation, the inference in (1) does not. However, as I argue below, there are reasons for thinking that differentiating between the cases in this way will be arbitrary.

\subsection{Situated Inference}

How might one argue that Louise's inference in (1) does not proceed via the assumption that Thelma wants to cooperate? A promising suggestion is that, rather than seeing the inference in (1) as a Gricean inference, based on assumptions concerning the speaker's intentions, or state of mind more generally, the inference can

\footnotetext{
${ }^{7}$ See also Lepore and Stone $(2015$, ch. 14$)$ for recent, relevant discussion.
} 
be explained simply as a logical or probabilistic inference relying on background assumptions. The claim would be that, in (1), Louise infers that Thelma is OK to drive - or perhaps that Thelma is probably OK to drive - solely on the basis of the information provided by what is said, i.e., that she has not been drinking, and background assumptions such as that Thelma knows how to drive, the road conditions are not unusual, etc.

To be sure, in (1), Louise does not come to believe that Thelma is OK to drive nor that she is probably OK to drive - on the basis of her inference. But granting this arguably does not rule out seeing Louise as inferring from what Thelma said that she is probably OK to drive. We might think of the case along the following lines. Louise notes that Thelma said that she has not been drinking. She has available the information that if Thelma has not been drinking, she is probably OK to drive. So Louise notes that what Thelma said implies that she is probably OK to drive. Indeed, it seems right to say that what Louise takes from Thelma's utterance in (1), among other things, is the observation that what she said implies that she is probably OK to drive. Hence, as long as this is all we mean by the claim that Louise infers that Thelma is probably OK to drive from what Thelma said, we are not precluded from seeing Louise as making this kind of inference. ${ }^{8}$

The main problem for the Gricean is that, if she endorses this approach to (1), it is hard to see how to motivate not applying it to cases like (2), as well. If one thinks that, in (1), Louise can infer that Thelma is probably OK to drive directly from what she says, and background assumptions, without recourse to an assumption concerning Thelma's cooperativeness, what is the argument for not accounting for (2) in the same way? As before, there seems to be no way of differentiating between the cases without begging the question.

In other words, this route appears to end up endorsing the view that, at least for cases the Gricean wants to explain as implicatures generated by Relation, most of these can be explained as ordinary inferences of the kind described above. Chris Gauker (2001) defends a position of this kind. According to Gauker, "the concept of conversational implicature is not a useful concept in the theory of language." (Gauker, 2001, 170) Instead, Gauker argues that cases the Gricean explains in terms of implicature are better explained as cases of what he calls situated inference. That is, the inferences that the Gricean thinks are inferences of implicatures are, for

\footnotetext{
${ }^{8}$ There is another sense of " $A$ infers $q$ from $p$," i.e., the sense in which this involves deducing $q$ from $p$ by consciously going through a process of valid reasoning. It is less plausible to think of Louise inferring that Thelma is probably OK to drive from what she says in this sense. But even if this is the preferred way of thinking of her reasoning, this clearly does not commit one to the claim that she comes to believe that Thelma is OK to drive.
} 
Gauker, simply inferences that are made on the basis of what is said, awareness of relevant contextual facts, and background assumptions.

Consider, for example, how Gauker explains Grice's $(1989,32)$ familiar case of the motorist whose car is out of gas. The dialogue is as in (3).

(3) A: I am out of gasoline.

$\mathrm{B}$ : There is a gas station around the corner.

Gauker writes,

To explain the success of communication in this case, we have to explain how $\mathrm{A}$ is able to conclude from what $\mathrm{B}$ explicitly says that he can get gas at the gas station around the corner. One explanation for A's drawing this conclusion might be Grice's own explanation of this, namely, that A recognizes that this is what $B$ must be supposing if $B$ is conforming to the Cooperative Principle. An alternative explanation is that $A$ reasons from the truth of what $B$ says and the character of the external situation to the conclusion that if there is a gas station around the corner then probably it is open and has gas to sell. Thoughts about what the speaker must have been thinking need not play any role whatsoever, and the speaker need not have intended the hearer to have any such thoughts. In my view, this is in fact the better explanation. (Gauker, 2001, 174)

Applied to the case of (1), the claim would be that Louise infers that Thelma is probably OK to drive on the basis of her recognition that Thelma said that she has not been drinking without proceeding by way of an assumption that Thelma wants to cooperate. ${ }^{9}$ And moreover, the same explanation would be given for run of the mill cases like (2).

It is not being denied that Thelma says what she does precisely with the intention that Louise should make the inference she does make. A view like Gauker's merely claims that Louise does not need the assumption that this is what Thelma intends as a premise for her inference. As Gauker says about the gas station example:

B might indeed intend that A will conclude that the gas station is open and has gas to sell (or maybe not), and in order for A to reach this conclusion $\mathrm{A}$

\footnotetext{
${ }^{9}$ We assume that Gauker's idea of reasoning "from the truth of" what is said can be construed along the lines suggested earlier, i.e., so as not necessarily to involve coming to believe the conclusion. In particular, we assume that an explanation along Gauker's lines can be given for cases where the hearer knows that what the speaker says is false. We can think of the hearer, in such cases, as reasoning from the supposition that what the speaker said is true.
} 
will have to pay attention to various features of the situation beyond what $B$ explicitly said; but there is no special reason for A to pay attention to what $\mathrm{B}$ might have had in mind in speaking, and B need not intend A to do so. (Gauker, 2001, 175)

I take it that the kind of inference Gauker describes might occur in many cases that, according to the Gricean, involve implicatures. In particular, we should grant that, in (1) and (2), Louise might infer from Thelma's utterance that she is probably OK to drive without proceeding by way of a premise concerning Thelma's state of mind.

Yet, even if Gauker is right about the inferences targeted by his discussion, it can be argued that there are inferences, which hearers routinely make, and which do rely on assumptions of cooperation. In both (1) and (2), Louise does not only infer that Thelma is probably OK to drive, and nor is that all that Thelma intended her to infer. In both cases Louise also infers that Thelma wanted to convey that she is OK to drive. The inference she makes is not simply one about the facts concerning whether Thelma is (probably) OK to drive. Louise also makes an inference about Thelma's goals in making her utterance. Similarly, in the motorist example of (3), that he can get gas at the gas station around the corner is not all that $\mathrm{A}$ infers from B's utterance. A will also infer that B wanted to convey that he can get gas at the gas station around the corner.

Generalizing, in many cases, the hearer not only makes an inference from what is said, but also infers something about what the speaker wanted to convey by saying what she did. And moreover, while Gauker might be right about the former type of inference, it is hard to see how to account for the latter kind of inference without seeing it as proceeding by way of assumptions about the speaker's efforts to cooperate.

In both (1) and (2), the most natural way of explaining how Louise infers from Thelma's utterance that Thelma wants to convey that she is OK to drive is arguably to see it as an inference that proceeds by way of the assumption that Thelma wants to cooperate. That is, the assumption that Thelma wants to provide an answer to the question, "Are you OK to drive?" And similarly, to explain how A infers, in (3), that $B$ wants to convey that $A$ can get gas at the gas station around the corner, one arguably needs to see the inference as proceeding via the assumption that $B$ wants to cooperate. That is, roughly, that B wants to make a contribution that is helpful in the situation where $A$ has just informed $B$ of being out of gas.

Against Gauker's wholesale rejection of the category of implicatures, then, the Gricean can claim that at least some inferences based on observation of what is said that hearers routinely make are best explained as proceeding by way of assump- 
tions concerning the hearer's attempt to cooperate.

However, of course, this hardly vindicates the further Gricean claim that cooperation involves truthfulness. In (1) Louise's inference that Thelma wants to convey that she is OK to drive is made despite Louise's recognition that Thelma is violating both the First Maxim of Quality and the Supermaxim of Quality. So if we are right that this inference is explained in terms of an assumption of cooperation, we still have reason to conclude that assuming that one's interlocutor is cooperating does not require assuming that she is being truthful.

\subsection{Bald-Faced Implicature}

At this point the Gricean might want to shift gears and focus more on what hearers must be assuming about what speakers want them to assume, rather than focusing more directly on what hearers assume about the extent to which speakers in fact comply with norms of truthfulness. Perhaps the Gricean should grant that, in (1), Louise does not assume that Thelma is being truthful, but point out that Louise nevertheless knows that Thelma intended her to believe that she is being truthful. In other words, it might be observed that, even if the inference in (1) does not proceed via the assumption that Thelma is in fact being truthful, it does proceed via an assumption that Thelma intended Louise to assume that she is being truthful.

Along these lines, the Gricean might want to recast her view as (IV).

(IV) $H$ assumes that $S$ is trying to satisfy other maxims in producing an utterance $u$ only if $H$ assumes that $S$ intended that $H$ assume that $S$ is not disregarding the First Maxim of Quality in producing $u$.

Arguably, if something like (IV) is right, this would be a way of vindicating the original idea that a speaker's assumption that a hearer is obeying maxims relies on her assuming that the speaker is being truthful, at least in the sense that it relies on an assumption that the speaker wanted to be perceived as being truthful.

(IV) is satisfied in normal cases of implicature, in which the hearer has reason to believe (or has no reason not to believe) that the speaker is saying something she believes to be true in order to implicate something she also believes to be true, as in (2) and (3). Moreover, (IV) still allows the Gricean to pursue the response to the position championed by Gauker we described above. That is, it might be granted that inferring that Thelma is probably OK to drive itself does not rely on assumptions about Thelma's intentions, but still, inferring that Thelma wanted to convey that she is probably OK to drive does rely on such assumptions. Indeed, it is reasonable to think that it does. 
The problem with this is that we can imagine cases in which not even (IV) is satisfied. In (1) Thelma is trying to be covertly untruthful, but is found out by Louise. But there are cases in which the speaker is not even trying to be covertly untruthful, but in which the relevant kind of inference is still made by the hearer. These are cases in which an implicature is derived from so-called bald-faced lies, that is, open or undisguised lies. ${ }^{10}$ As we might say, these are cases of bald-faced implicature.

Suppose, for example, that it is common knowledge between Thelma and Louise that Thelma has been drinking. That is, Thelma knows that Louise knows that Thelma knows that Louise knows, etc., that Thelma has been drinking. If our dialogue takes place in this setting, Louise will still infer that Thelma wanted to convey that she is probably OK to drive. Of course, as before, she will not believe that Thelma is probably OK to drive. But she will still infer that Thelma wanted to convey that she is, and indeed, Louise will recognize (correctly) that Thelma wanted her to recognize that she wanted her to do so.

Again, it is hard to see how to explain this inference except as based on an assumption about Thelma's wants to cooperate, and in particular, that she wants to satisfy Relation. And so, (IV) still does not manage to spell out a way of upholding the Gricean idea that a hearer is assumed to be cooperative, in the sense of obeying maxims, only to the extent that she is assumed to be truthful.

\section{Implicature and Rationality}

\subsection{Implicature without Truthfulness}

I have argued that at least some inferences that are drawn on the basis of assumptions of cooperation are made independently of assumptions of truthfulness. Should we think of these cases as inferences of conversational implicatures? I think we should. As is often emphasized, Grice stresses repeatedly that an implicature is an inference that is needed for preserving the presumption that the speaker is observing the maxims, or at least the Cooperative Principle. For example, in the passage we quoted earlier, Grice says,

\footnotetext{
${ }^{10}$ For discussion, see Carson (2006), Sorensen (2007), Fallis (2009), Stokke (2013). Some writers, e.g., Lackey (2013), object that, in the relevant examples, the speaker is nevertheless trying to hide information from the hearer. Even if such critics are right, this is irrelevant to my argument, since, in the relevant cases, the hearer is still not assuming that the speaker intended the hearer to assume that the speaker is not violating the First Maxim of Quality.
} 
[T] calculate a conversational implicature is to calculate what has to be supposed in order to preserve the supposition that the Cooperative Principle is being observed [...]. (Grice, 1989, 39-40, emphasis added)

Similarly, consider Grice's statement of three necessary conditions on implicature: ${ }^{11}$

A man who, by (in, when) saying (or making as if to say) that $p$ has implicated that $q$, may be said to have conversationally implicated that $q$, provided that (1) he is to be presumed to be observing the conversational maxims, or at least the Cooperative Principle; (2) the supposition that he is aware that, or thinks that, $q$ is required in order to make his saying or making as if to say $p$ (or doing so in those terms) consistent with this presumption; and (3) the speaker thinks (and would expect the hearer to think that the speaker thinks) that it is within the competence of the hearer to work out, or grasp intuitively, that the supposition mentioned in (2) is required. (Grice, 1989, 30-31, emphasis added)

Louise's inference that Thelma wants to convey that she is OK to drive, in (1), fits this pattern. As suggested earlier (see section 3.1), in (1), the assumption that Thelma wants to cooperate amounts to the assumption that she wants to convey an answer to the question, "Are you OK to drive?" Since there are only two answers to this polar question, assuming that Thelma wants to convey an answer means assuming that she wants to convey either a yes or a no. If Louise were to infer that Thelma wanted to convey that she is not OK to drive, this would make a mystery of why Thelma said that she has not been drinking. So in order to reconcile that Thelma said what she did with the assumption that she wants to convey an answer to the question, "Are you OK to drive?" Louise must infer that Thelma wanted to convey that she is OK to drive.

So Louise's inference that Thelma wanted to convey that she is OK to drive satisfies Grice's characterizations of conversational implicatures. Moreover, as suggested earlier (see section 2.3), that Thelma wanted to convey that she is OK to drive is something Thelma intended Louise to infer from her utterance.

As noted earlier, Saul (2002) distinguishes between utterer-implicatures and audience-implicatures, the former being, roughly, implicatures the speaker intended the audience to infer, and the latter being, roughly, implicatures the audience in fact infers from what the speaker says. The kind of examples I have appealed to - as represented by (1) - are cases where these coincide. Hence, even if one is sympathetic to this kind of distinction, one should agree that cases like (1) are cases of implicature in both senses.

\footnotetext{
${ }^{11}$ See also (Grice, 1989, 370).
} 
By contrast, Stephen Neale (1992) suggests that something is an implicature only if it is intended, and he argues that this condition is grounded in Grice's view of implicatures as an aspect of speaker meaning:

A necessary condition on conversational implicatures [...] is that they are intended. This follows [...] at least from the fact that (a) what $U$ implicates is part of what $U$ means, and (b) what $U$ means is determined by $U$ 's communicative intentions. (Neale, 1992, 528)

To repeat, in (1), Thelma intends that Louise infer that she is OK to drive. And furthermore, the latter content is something that Thelma meant, in the Gricean sense. For Grice, to say that a speaker $S$ meant that $p$, roughly, is to say that $S$ intended that the hearer $H$ come to believe that $p$ partly as a result of recognizing this intention. ${ }^{12}$ In (1) Thelma wants Louise to believe both that she has not been drinking and that she is OK to drive. Both these things are part of what Thelma means, on this occasion.

Finally, some writers defend the view that, contrary to Grice's own account, implicatures do not rely on cooperation. For example, Wayne Davis (1998) argues that "Conversational implicatures may exist when there is no presumption on anyone's part that the speaker is observing the Cooperative Principle." $(1998,115)$ Part of Davis's case for this conclusion is based on cases similar to our case of (1). Here is one of his examples (Davis, 1998, 116):

(4) Karen: Were you with Jennifer last night?

George: I was out drinking with the guys.

Davis claims that, "George implicated that he was not with Jennifer last night. He may have implicated this even if Karen knows he is lying, having seen George and Jennifer together." (Davis, 1998, 116)

For Davis, a speaker's conversationally implicating something is chiefly a matter of the speaker having certain intentions. ${ }^{13}$ He takes cases like (4) to demonstrate that speakers may have such intentions even when they are not presumed to be cooperating. Davis writes,

What $S$ implicates cannot be due even in part to what others presume or know about $\mathrm{S}$. To implicate something is to mean or imply it in a certain way. And as Grice [...] correctly observed, to mean or imply something is to have certain intentions. But $S^{\prime}$ s intentions do not depend on what anyone else presumes. (Davis, 1998, 122)

\footnotetext{
${ }^{12}$ See Neale $(1992,515)$.

${ }^{13}$ See Saul $(2002,240-241)$ for criticism of this view.
} 
Accordingly, Davis thinks that, in (4), George may have intended to convey that he was not with Jennifer last night, even if Karen does not take him to be cooperating. This I take to be hard to deny. But, by contrast, what I have been arguing for is a point concerning the way hearers infer, or work out, implicatures. I take the idea that such inferences rely on assumptions of cooperation, and perhaps on assumptions of truthfulness, to be a more interesting thesis than the one Davis is targeting. It is worth stressing, however, that my arguments do not conflict with Davis's case for the conclusion that speakers may intend implicatures even when they are not presumed to be cooperating.

I conclude that the case of (1) has the characteristics of a case of conversational implicature, independently of how one thinks of the issues concerning the difference between utterer-implicature and audience-implicature, or the issue of whether being intended by the speaker is a necessary condition on implicature. In these respects, (1) is parallel to (2). Hence, we should conclude that conversational implicature - and more broadly, the kind of communication that Grice identified as relying on cooperation - does not rely on a presumption of truthfulness. ${ }^{14}$

\subsection{Untruthfulness and the Rational Basis of Cooperation}

According to what I have been arguing, the conclusion that Thelma wants to convey that she is OK to drive is arrived at via the assumption that Thelma wants to satisfy the Maxim of Relation, or at least the Cooperative Principle. We have seen that this assumption may be in place even when the hearer knows that the speaker is not observing quality maxims, i.e., even when the hearer knows the speaker is being untruthful.

However, it might be asked, why should one assume that one's interlocutor is being cooperative when one can see that they are being untruthful? Familiarly, Grice was adamant that the practice of following the Cooperative Principle and the maxims has a rational basis. As he says,

I would like to be able to think of the standard type of conversational practice not merely as something that all or most do in fact follow but as something

\footnotetext{
${ }^{14}$ This conclusion is compatible with other views according to which truthfulness is a prerequisite for communicative practices. For example, Lewis (1969), (1975) held that a language $L$ is used by a population $P$ if and only if there is a convention of truthfulness and trust in $L$ among the members of $P$. The fact that Gricean inferences may be drawn in the absence of assumptions of truthfulness is compatible with the view that conventions of truthfulness and trust are necessary for our practice of using a particular language to communicate with each other.
} 
that it is reasonable for us to follow, that we should not abandon. (Grice, 1989,

29)

Given this, one way of suggesting an explanation of the basis for Louise's assumption that Thelma wants to cooperate in (1) is to say that she does so simply because she is following a practice that is already established, and which has a rational underpinning. But it might be felt that it would be preferable if it could be established that, even in the case of (1), the assumption that Thelma wants to cooperate can be seen as rational, and not just because it constitutes following a practice that is otherwise rational.

Put differently, can it be rational to assume that someone one knows is being untruthful is observing Gricean maxims, or at least the Cooperative Principle? A full response to this question is far beyond the scope of this paper. But I want to end by suggesting at least some reason for thinking that it can be given an affirmative answer.

It is not unreasonable to think that we need to be able to work out what people want to convey to us, even when we know they are being untruthful. Doing so is helpful, for example, for evaluating the overall trustworthiness of the speaker, which in turn is useful for evaluating what they might tell us in the future, or indeed evaluating what they have told us in the past. More generally, discovering what someone will attempt to make us believe - even when we already know the truth of the matter - may be useful for learning about their character, or for learning about their intentions in the more immediate situation. If this is right, it at least goes some way toward explaining why it is reasonable to take speakers as cooperating, in the sense of obeying maxims and trying to make pertinent contributions to conversations, even if one knows they are being untruthful.

\section{References}

Benton, M. (in press). Gricean quality. Forthcoming in Nô̂s.

Carson, T. (2006). The definition of lying. Noûs, 40, 284-306.

Davis, W. (1998). Implicature: intention, convention, and principle in the failure of Gricean theory. Cambridge and New York: Cambridge University Press.

Fallis, D. (2009). What is lying? Journal of Philosophy, 106, 29-56. 
Gauker, C. (2001). Situated inference versus conversational implicatures. Noûs, 35(2), 163-.189.

Grice, H. (1989). Studies in the way of words. Cambridge, MA: Harvard University Press.

Lackey, J. (2013). Lies and deception: An unhappy divorce. Analysis, 73(2), 236248.

Lepore, E., \& Stone, M. (2015). Imagination and convention: Distinguishing grammar and inference in language. Oxford and New York: Oxford University Press.

Lewis, D. (1969). Convention: A philosophical study. Cambridge, MA: Harvard University Press.

Lewis, D. (1975). Languages and language. In Philosophical papers (Vol. I, p. 163188). Oxford and New York: Oxford University Press, 1983.

Neale, S. (1992). Paul Grice and the philosophy of language. Linguistics and Philosophy, 15, 509-559.

Saul, J. (2002). Speaker meaning, what is said, and what is implied. Nô̂s, 36(2), 228-248.

Sorensen, R. (2007). Bald-faced lies! Lying without the intent to deceive. Pacific Philosophical Quarterly, 88, 251-264.

Stokke, A. (2013). Lying and asserting. Journal of Philosophy, CX(1), 33-60.

Thomason, R. (1990). Accommodation, meaning, and implicature: Interdisciplinary foundations for pragmatics. In P. Cohen, J. Morgan, \& M. Pollack (Eds.), Intentions in communication (pp. 325-363). Cambridge, Mass. and London: MIT Press. 